\title{
NOTES
}

\section{Gas-Permeation Control by PET Membranes with Nanosized Pores}

\author{
Shuichi TAKAHASHI ${ }^{\dagger},{ }^{\dagger \dagger}$, Masaru YoshIDA*, Masaharu ASANO*, and Tsutomu NAKAGAWA \\ Department of Industrial Chemistry, Meiji University, 1-1-1 Higashi-mita, Tama-ku, Kawasaki 214-8571, Japan \\ *Department of Material Development, Takasaki Radiation Chemistry Research Establishment, \\ Japan Atomic Energy Research Institute, 1233 Watanuki-machi, Takasaki 370-1292, Japan
}

(Received January 28, 2003; Accepted October 2, 2003)

KEY WORDS Gas-Permeation / PET / Heavy-ion Irradiation / Etching / Nanosized Pore / Knudsen Flow /

PET is a polymer widely used for fibers, films, and bottles. The gas permeability properties of PET, which is often used as a gas-barrier film, can easily be modified using techniques such as ion irradiation. PET membranes have higher mechanical strength and undergo various chemical changes in response to ion irradiation easily and thus are optimum material for gas-permeation membrane. ${ }^{1-6}$ We previously reported the effects of heavy-ion irradiation on the gas permeation of a PET membrane. ${ }^{7}$ A portion of the heavy-ion irradiated PET membranes exhibits Knudsen flow during gas-permeation measurement. Energetic heavy ions are ionizing particles that create zones of high-density excitations and ionizations as they pass through membrane materials and cause many effects due to a high local dose within ion tracks. We thus applied etching utilizing $\mathrm{NaOH}$ solution as an etchant control nanosized pores of the heavy ion-irradiated PET membranes. In the past, much attention was paid to track etching in various polymer membranes with respect to applications in nuclear fusion, medical, material technology and other fields. ${ }^{8-16}$

In the present study, PET membranes were irradiated at a fluence of $3 \times 10^{9}$ ions $/ \mathrm{cm}^{2}$ and etched in $6 \mathrm{~N}$ or $1 \mathrm{~N} \mathrm{NaOH}$ solution at $60^{\circ} \mathrm{C}$. Etching time was controlled to observe changes in the gas-permeation behavior depending on the etching. Pore-size distribution in the membranes exhibiting Knudsen flow during gas-permeation measurement was observed using the nano-permporometer and permporometer.

\section{EXPERIMENTAL}

The poly(ethylene terephthalate) (PET) membrane used in this study was obtained from Hoechst Japan Co., Ltd. Thickness of the PET membrane was 12 $\mu \mathrm{m}$, and each had a semicrystalline structure of approximately $40 \%$ crystallinity and density of $1.4 \mathrm{~g} / \mathrm{cm}^{3}$.

Xe ions were used at a fluence of $3 \times 10^{9}$ ions $/ \mathrm{cm}^{2}$ for heavy-ion irradiation. A PET membrane of $12 \mu \mathrm{m}$ thickness was cut into a $50 \times 50 \mathrm{~mm}$ squares and then attached to a glass $50 \times 50 \times 1 \mathrm{~mm}$ plate. The chamber for formation of the ion-track pores in the membrane, connected to the Azimuthally Varying Field (AVF) cyclotron in the Takasaki Ion Accelerators for Advanced Radiation Applications (TIARA), Japan Atomic Energy Research Institute (JAERI), was designed for alternate use of turntable-type and roll-type film-carrying systems. Irradiation was performed under vacuum. The apparatus for Xe ion irradiation has been described previously. ${ }^{7}$

We applied etching using $\mathrm{NaOH}$ solution to control nanosized pores. PET membranes irradiated at a fluence of $3 \times 10^{9}$ ions $/ \mathrm{cm}^{2}$ were etched in $6 \mathrm{~N}$ or $1 \mathrm{~N}$ $\mathrm{NaOH}$ solution at $60^{\circ} \mathrm{C}$ as shown in Figure 1. Etching time was controlled to observe changes in the gas-per-

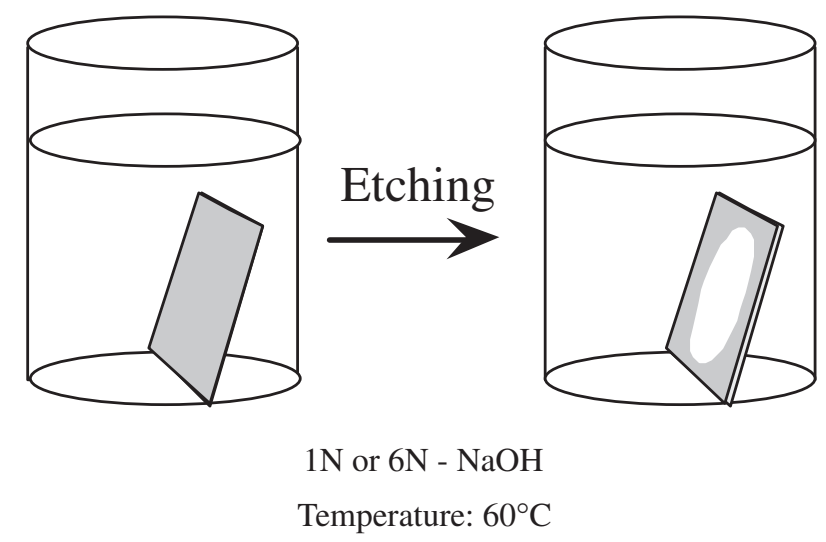

Figure 1. Illustration of the nuclear track membrane-production method.

\footnotetext{
${ }^{\dagger}$ To whom correspondence should be addressed (Tel: 1-512-471-6675, Fax: 1-512-471-0542, E-mail: shuichi@che.utexas.edu).

${ }^{\dagger}$ Present address: Department of Chemical Engineering, The University of Texas at Austin
} 
meation behavior depending on the etching.

Gas permeability of the membranes was determined by vacuum-pressure methods. ${ }^{17}$ Measurement procedures for the gas-permeation were carried out according to previously established guidlines. ${ }^{17-19}$ The permeability coefficient $(P)$ was calculated from the slope of time-pressure curves in the steady state. Gas-permeation measurements were carried out for pure $\mathrm{He}, \mathrm{N}_{2}, \mathrm{O}_{2}$, and $\mathrm{CO}_{2}$ at $303 \mathrm{~K}$. The gases were used without further purification.

When pore size of membrane is smaller than the mean free path of the gas molecules as noted above, gas separation occurs. In the range of $r / \lambda<1$ ( $r$, radius of the pore, $\lambda$, mean free path), gas permeation of the penetrant molecules is considered to exhibit Knudsen flow. ${ }^{20}$ This implies that gas molecules interact with pore walls much more frequently than with other molecules and low-molecular weight gases are able to diffuse more rapidly than the heavier ones. In a vacuum state, the difference in permeation rates of two components is inversely proportional to the square root of the ratio of molecular weights. In the case of the membrane, Knudsen flow is expressed by the following equation:

$$
Q=\frac{4}{3} r \varepsilon \cdot\left(\frac{2 R T}{\pi M}\right)^{\frac{1}{2}} \cdot \frac{\left(p_{1}-p_{2}\right)}{\ell \cdot R T}
$$

where $Q$ is the amount of permeant, $r$, radius of a pore, $\varepsilon$, porosity, $M$, molecular weight of the penetrant, $p_{1}$ and $p_{2}$, pressures of the penetrant at the feed side and permeate side, respectively, and $\ell$, membrane thickness.

Pore-size distribution was observed using a nanopermporometer from the Seika Sangyo Corporation. Nano-permporometer measurement was initiated by measuring the permeability of dry helium and checking the steady permeability at the measurement temperature. Vapor pressure was gradually increased stepwise to a specific partial pressure, until helium permeation was nearly blocked by capillary-condensation. The feed and permeate flow rate were computercontrolled or measured. Helium was used as a noncondensable gas, and the liquid used as condensable vapor was hexane.

Maximum pore size was also measured by the bubble-point method using a Seika Sangyo Corporation Permporometer, from which pore size can be calculated based on the Laplace equation from the pressure required to force air through a liquid-filled pore.

The tensile stress-strain curve at room temperature was measured using a tensile testing machine (SHIMADZU AGS-H 5kN AUTOGRAPH) with a crosshead speed of $5 \mathrm{~mm} / \mathrm{min}$. The capacity of the clamp assembly was $5 \mathrm{kN} / 500 \mathrm{kgf}$. Sample specimens

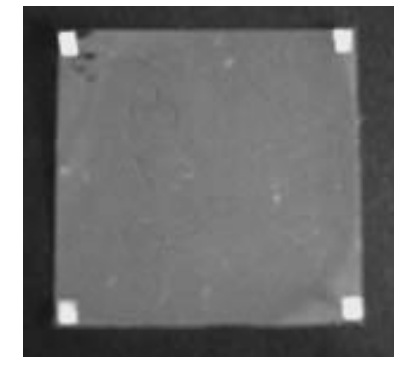

(a)

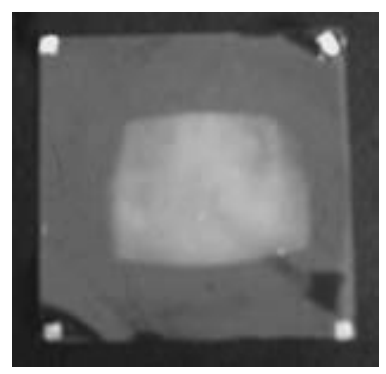

(b)
Figure 2. Visual effects of etching on PET membranes. (a) Heavy Ion Irradiated PET $\left(3.0 \times 10^{9}\right.$ ions $\left./ \mathrm{cm}^{2}\right)$, (b) $120 \mathrm{~s}$ etching $\left(6 \mathrm{~N}-\mathrm{NaOH} 60^{\circ} \mathrm{C}\right)$ and 28 min etching $\left(1 \mathrm{~N}-\mathrm{NaOH} 60^{\circ} \mathrm{C}\right)$.

were cut using a DUMBBELL SDMK-1000-D cutter (DUMBBELL Co., Ltd.) according to JIS K-6251-6.

\section{RESULTS AND DISCUSSION}

Pores were created in the PET membrane by heavyion irradiation essentially as described previously. ${ }^{7}$ Gas permeation in the dried state increased and exhibited Knudsen flow. It was very difficult to control gas permeation. We therefore attempted etching using $\mathrm{NaOH}$ solution to control gas permeation and poresize of the heavy ion-irradiated PET membrane. The PET membranes irradiated at a fluence of $3 \times$ $10^{9}$ ions $/ \mathrm{cm}^{2}$, were etched in $6 \mathrm{~N}$ or $1 \mathrm{~N} \mathrm{NaOH}$ solution at $60^{\circ} \mathrm{C}$. Etching time was controlled so that its effects on gas-permeation dependent on etching could be observed. Figure 2 shows effects of etching on a heavy ion-irradiated PET membrane. A white color on the PET membrane gradually developed with increase in etching time. It is thought that an etchingcone formed by etching changed the refractive index. Penetration into etched pores was judged based on whiteness and etching time.

The relationship between gas permeability and the reciprocal of the square root of gaseous molecular weight is shown in Figure 3. Change in gas permeability of etched membranes was confirmed. Permeability coefficients of membranes, exposed to alkali etching for more than $120 \mathrm{~s}$, increased with etching time. Gas permeation may thus exhibit Knudsen flow. Increase in permeability depends on etching time. In the case of membranes etched for $28 \mathrm{~min}$ by the $1 \mathrm{~N}$ $\mathrm{NaOH}$ etchant, higher permeability coefficients were obtained, causing greater damage to the ion track of PET. None of the membranes of $6 \mathrm{~N}-60 \mathrm{~s}, 6 \mathrm{~N}-110 \mathrm{~s}$, $1 \mathrm{~N}-26 \mathrm{~min}$ and PET in Figure 3 formed penetrating pores, and all exhibited the same gas-permeation behavior as untreated PET, indicating pore-diameters to predict the gas-permeation procedure.

Pore-size distribution and maximum pore-diameter in the membranes exhibiting Knudsen flow during 


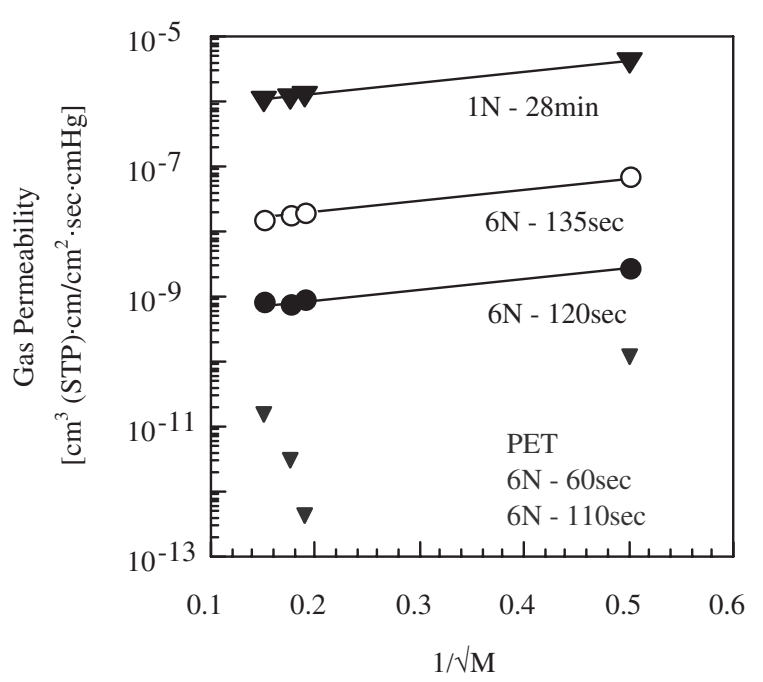

Figure 3. Relationship between the permeability rate and reciprocal of the square root of gaseous molecular weight at $303 \mathrm{~K}$.

Table I. Pore-diameter distribution and maximum pore diameter as a function of etching-time or etchant in the etched PET membranes. The membranes were irradiated with Xe ion $\left(3 \times 10^{9}\right.$ ions $\left./ \mathrm{cm}^{2}\right)$

\begin{tabular}{ccccc}
\hline Etchant & $\begin{array}{c}\text { Etch-temp. } \\
\left({ }^{\circ} \mathrm{C}\right)\end{array}$ & Etch-time & $\begin{array}{c}\text { Pore diameter } \\
\text { distribution } \\
(\mathrm{nm})\end{array}$ & $\begin{array}{c}\text { Maximum } \\
\text { pore diameter } \\
(\mathrm{nm})\end{array}$ \\
\hline $6 \mathrm{~N}-\mathrm{NaOH}$ & 60 & $60 \mathrm{~s}$ & - & - \\
$6 \mathrm{~N}-\mathrm{NaOH}$ & 60 & $110 \mathrm{~s}$ & - & - \\
$6 \mathrm{~N}-\mathrm{NaOH}$ & 60 & $120 \mathrm{~s}$ & $\begin{array}{l}1.5-3.8 \\
6.7-9.2\end{array}$ & 40.6 \\
& & & $3.8-5.0$ & 38.2 \\
$6 \mathrm{~N}-\mathrm{NaOH}$ & 60 & $135 \mathrm{~s}$ & $22.6-38.2$ & - \\
$1 \mathrm{~N}-\mathrm{NaOH}$ & 60 & $26 \mathrm{~min}$ & - & - \\
$1 \mathrm{~N}-\mathrm{NaOH}$ & 60 & $28 \mathrm{~min}$ & $23.9-39.8$ & 39.8 \\
\hline
\end{tabular}

the gas-permeation measurements, were observed using nano-permporometer and permporopmeter, respectively. Table I shows pore-diameter distribution and maximum pore-diameter as a function of etching-time and etchant concentration in etched PET membranes. All membranes of $6 \mathrm{~N}-60 \mathrm{~s}, 6 \mathrm{~N}-110 \mathrm{~s}$, $1 \mathrm{~N}-26$ min exhibited the same gas-permeation behavior as untreated PET and contained no penetrating pores. Erosion of the etchant may form etching-cones along the core region, produced by the heavy-ion irradiation, as shown in Figure 4b. This was reported previously. ${ }^{21}$ When $6 \mathrm{~N} \mathrm{NaOH}$ is used as a etchant, porediameter distribution widely varies. However, the pore-diameter of membrane at more than $120 \mathrm{~s}$ of etching was dependent on etching time. As a result, the size of the pore was controlled on a nanometer scale. Etchant at relatively high concentrations is thus very useful for producing smaller nanosized pores in a short time, but pore-diameter distribution varies widely. In contrast, etchant at lower concentrations produc- es more homogeneous pore-diameters in heavy ion-irradiated PET membranes. Etchant at lower concentrations may depress the heterogeneous pore diameter, but precise control of the smaller nanosized pores is difficult. In all membranes with pores formed by etching maximum pore diameter measured by the bubblepoint method is approximately $40 \mathrm{~nm}$. Therefore, the diameter of the core region, created as ionizing particles passing through the membrane materials as shown in Figure 4a, is about $40 \mathrm{~nm}$.

The tensile stress-strain behavior of materials studied in this investigation is represented in Figure 5. As described in a previous paper. ${ }^{5}$ PET has high tensile strength and elongation, i.e., so-called tough material.

(a) Heavy ion irradiated membrane

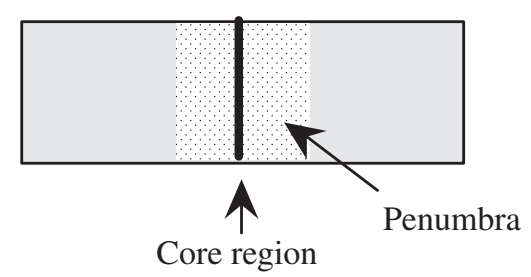

(b) Heavy ion irradiation + Etching membrane

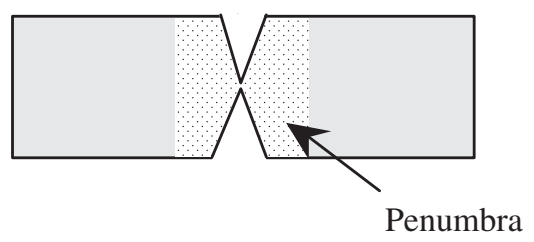

Figure 4. Representation of a modified membrane. (a) Heavy ion-irradiated membrane, (b) Heavy-ion irradiation + Etching membrane.

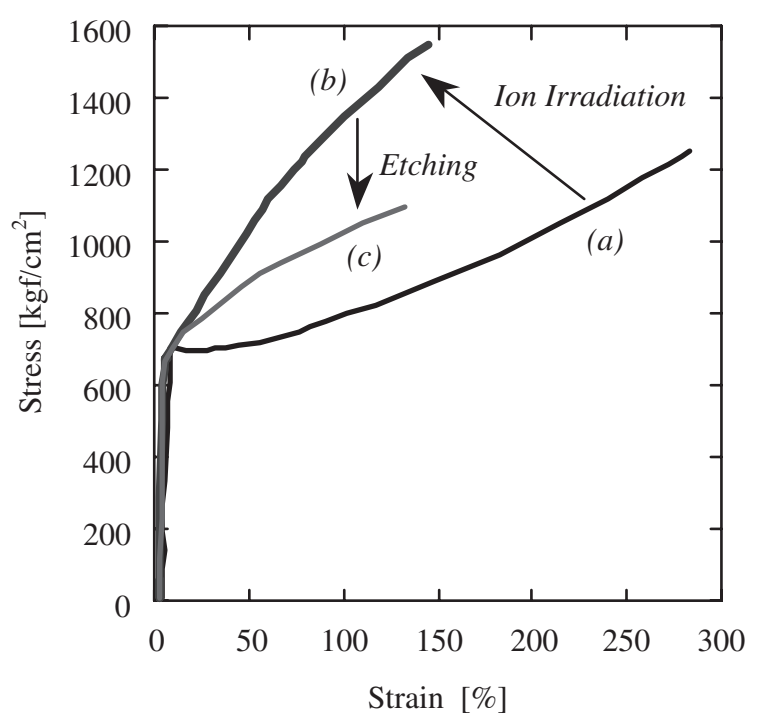

Figure 5. Typical stress-strain curves for (a) PET, (b) Xe ion irradiated PET $\left(3.0 \times 10^{9}\right.$ ions $\left./ \mathrm{cm}^{2}\right)$ and (c) Ion-irradiated PET $\left(3.0 \times 10^{9}\right.$ ions $\left./ \mathrm{cm}^{2}\right)$ etched by $6 \mathrm{~N}-\mathrm{NaOH}$ for $180 \mathrm{~s}$. 
The PET used in this study was tough material with elongation breaking at around $275 \%$ [Line (a) in Figure 5]. Xe-ion irradiation of $3 \times 10^{9}$ ions $/ \mathrm{cm}^{2}$ enhanced the tensile strength but decreased the elongation at the break. However, elongation of an ionirradiated membrane was reduced to one-half that of PET [Line (b) in Fig. 5]. Significant cross-linking may thus occur after heavy-ion irradiation. The cross-linking region is known as the penumbra, as reported in an earlier chapter. ${ }^{5}$ Decreasing elongation at break may contribute to polymer chain scission by ion irradiation. Elongation at the break and the tensile strength was decreased by etching [Line (c) in Figure 5]. The curve line is similar to Line (b) and shows residual cross-linking. Decreasing elongation at the break and tensile strength are due to decreasing cross-linking in response to etching and production of penetrating pores, respectively. The formation of cracks in response to etching was not confirmed. However, these membranes involve have relatively high tensile strength.

\section{CONCLUSION}

PET membranes, irradiated at a fluence of $3 \times 10^{9}$ ions $/ \mathrm{cm}^{2}$, were etched in $6 \mathrm{~N}$ or $1 \mathrm{~N} \mathrm{NaOH}$ solution at $60^{\circ} \mathrm{C}$. Etching time was controlled to observe changes in gas-permeation behavior depended on etching. Heavy ion-irradiated PET membranes gradually developed and became white with increase in etching time. Permeability coefficients of membranes subject to etching in alkali for more than $120 \mathrm{~s}$ increased with etching time. Permeation behavior of the membranes exhibited Knudsen flow. Poresize distribution and maximum pore-diameter in the membranes, which exhibited Knudsen flow during gas-permeation measurement, were observed using a nano-permporometer and permporometer, respectively. Pore size was thus controlled on a nanometer scale. Etchant at high concentrations is thus very useful for producing smaller nanosized pores in a short time, but pore-diameter distribution widely varies. Also, the diameter of the core region, created as ionizing particles pass through the membrane materials, is approximately $40 \mathrm{~nm}$. The stress-strain curve of etched PET membranes is similar to the one for the heavy ion-irradiated PET membranes and suggests residual cross-linking. Mechanical properties of the etched PET membranes may decrease due to decreasing cross-linking region in response to etching and production of penetrating pores. Etched heavy ion-irradiated PET membranes may thus be used as membranes with nanosized pores owing to high tensile strength.
Acknowledgment. The present study was supported by REIMEI Research Resources of the Japan Atomic Energy Research Institute.

\section{REFERENCES}

1. R. M. Papaleo, M. A. deAraujo, and R. P. Livi, Nucl. Instrum. Methods Phys. Res. B, 65, 442 (1992).

2. K. Ciesla and W. Starosta, Nucl. Instrum. Methods Phys. Res. B, 105, 115 (1995).

3. C. Trautmann, T. Steckenreiter, H. Fuess, and E. Balanzat, Nucl. Instrum. Methods Phys. Res. B, 131, 159 (1997).

4. A. Biswas, S. Lotha, D. Fink, J. P. Singh, D. K. Avasthi, B. K. Yadav, S. K. Bose, D. T. Khating, and A. M. Avasthi, Nucl. Instrum. Methods Phys. Res. B, 159, 40 (1999).

5. S. Takahashi, M. Yoshida, M. Asano, M. Notomi, and T. Nakagawa, Nucl. Instrum. Methods Phys. Res. B, accepted for publication 2004.

6. Z. Zhu, Y. Sun, C. Liu, J. Liu, and Y. Jin, Nucl. Instrum. Methods Phys. Res. B, 193, 271 (2002).

7. S. Takahashi, M. Yoshida, M. Asano, T. Tanaka, and T. Nakagawa, J. Appl. Polym. Sci., 82, 206 (2001).

8. M. Asano, M. Yoshida, H. Omichi, N. Nagaoka, H. Kubota, R. Katakai, N. Reber, and R. Spohr, Hosyasen, 22, 61 (1996).

9. M. Yoshida, N. Nagaoka, M. Asano, H. Omichi, H. Kubota, K. Ogura, J. Vetter, R. Spohr, and R. Katakai, Nucl. Instrum. Methods Phys. Res. B, 122, 39 (1997).

10. M. Yoshida, M. Asano, A. Safranj, H. Omichi, R. Spohr, J. Vetter, and R. Katakai, Macromolecules, 29, 8987 (1996).

11. M. Tamada, M. Yoshida, M. Asano, A. Safranj, H. Omichi, R. Katakai, R. Spohr, and J. Vetter, Polymer, 33, 3169 (1992).

12. K. Ogura, T. Hattori, T. Naito, K. Nakano, and T. Takahashi, Nucl. Tracks Radiat. Meas., 22, 921 (1993).

13. T. Kobayashi and M. Fujii, Nucl. Tracks Radiat. Meas., 15, 175 (1988).

14. M. Berndt, J. Krause, G. Siegmon, and W. Enge, Nucl. Tracks, 12, 985 (1986).

15. P. Apel, A. Schulz, R. Spohr, C. Trautmann, and V. Vutsadakis, Nucl. Instrum. Methods Phys. Res. B, 146, 468 (1998).

16. P. Yu. Apel, Yu. E. Korchev, Z. Siwy, R. Spohr, and M. Yoshida, Nucl. Instrum. Methods Phys. Res. B, 184, 337 (2001).

17. T. Nakagawa, H. B. Hopfenberg, and V. Stannett, J. Appl. Polym. Sci., 15, 231 (1971).

18. J. Crank and G. S. Park, Ed., "Diffusion in Polymers", Academic Press, London, 1968.

19. Y. Osada and T. Nakagawa, "Membrane Science and Technology", Dekker, New York, 1992.

20. W. S. W. Ho and K. K. Sirkar, "Membrane Handbook", Van Nostrand Reinhold, New York, 1992.

21. M. Berndt, J. Krause, G. Siegmon, and W. Enge, Nucl. Tracks, 12, 985 (1986). 